\title{
Enumeration of Rumen Micro-organisms
}

\author{
BY A. C. I. WARNER \\ Division of Animal Physiology, C.S.I.R.O., Ian Clunies Ross Animal Research \\ Laboratory, Prospect, N.S.W., Australia
}

(Received 24 July 1961)

\begin{abstract}
SUMMARY
Techniques are described for counting and differentiating the rumen microbial population. The rumen liquor is fixed and preserved in formol saline, and counts are made in two counting chambers, whose dimensions depend on the size of the organism to be counted; stained smears of the bacteria are also examined. Counts made on small samples of rumen liquor obtained through a fistula have been compared with counts on samples of the entire rumen contents; the ratio of these counts seemed to depend on the particular organism counted, the ration and the time after feeding. The importance of differential as opposed to total counts is emphasized.
\end{abstract}

\section{INTRODUCTION}

Most workers in rumen microbiology have been interested either in the bacteria or in the protozoa, though both groups have been shown to be important in the rumen and the possibilities of interaction are almost infinite. Within these groups, there are no generally accepted methods for counting the microbial population, though this is an important starting point in any study on the rumen microbial population or its metabolic products.

Rumen bacteria have been counted by three methods, direct counts in counting chambers or in stained smears, or viable counts. Smith \& Baker (1944) used an ordinary haemocytometer $(0 \cdot 1 \mathrm{~mm}$. deep), staining the bacteria with iodine so that only a portion of the total was counted. Van der Wath (1948) and several others used a Petroff-Hauser counting chamber which, being only $0.02 \mathrm{~mm}$. deep, is better adapted to counting bacteria, while Warner (1956) used the similar Helber counting chamber. Stained smears, analogous to the Breed milk smear, have been used by Köhler (1940) and others; Lengemann \& Allen (1955) using this method counted only the bacteria associated with the solid residue after straining the rumen contents. These methods do not, however, distinguish between dead and living cells; on the other hand, cultural methods may not grow all organisms capable of multiplying in the rumen, owing to failure to reproduce in the cultural conditions some essential feature of the rumen environment. Most workers have used strained rumen liquor as inoculum, though Bryant \& Burkey (1953) have shown a very much (about six times) greater colony count using the solid fraction of rumen contents; these workers did not, however, calculate the total number of bacteria in whole rumen contents.

The rumen ciliate protozoa have also been counted by various methods. The most common has been to use blood-counting chambers of various kinds. Although Ferber (1928) used a Fuchs-Rosenthal chamber, $0.2 \mathrm{~mm}$. deep, subsequent workers 
used ordinary haemocytometers, $0.1 \mathrm{~mm}$. deep, until Warner (1956) used the Manners chamber, $0 \cdot 2 \mathrm{~mm}$. deep. Oxford (1955) pointed out the disadvantages of using these chambers when the protozoa to be counted could exceed $200 \mu$ in length and suggested using techniques similar to those used by Adam (1951) for counting the ciliate protozoa in the caecum and colon of the horse; Boyne, Eadie \& Raitt (1957), in a comprehensive and critical study, and Moir \& Somers (1957) and Purser \& Moir (1959) have done this. Hungate (1942) and Gutierrez (1955) counted cells as they were removed from a drop into a capillary tube under a dissecting microscope, while Van der Wath \& Myburgh (1941) stained a small drop and counted all the cells in it. Again, most workers have been content to use strained rumen liquor for counting purposes; only Boyne et al. (1957) took considerable care to wash out the protozoa during the straining process.

No records of counts of flagellate protozoa have been found.

The direct counting techniques have mainly been used to give total numbers of protozoa or bacteria, with very little differentiation within those groups; the viable counts of bacteria have been used to determine mainly either the total numbers or the numbers of a single or a few species of interest at the moment: very few comprehensive differential counts have been published.

Sampling from the rumen is difficult. Rumen contents are a heterogeneous mixture of solids and liquid, often with marked stratification of the solids. The 'free' microorganisms are suspended in, and usually considered with, the liquid portion.

Satisfactory sampling of the solids, to which a large but variable part of the bacterial population is 'fixed', would seem impossible short of removing all or at least a large part of the rumen contents for mixing; return of this material to the rumen after sampling is desirable for the health of the animal, and some damage to the microbes in the process would appear possible. Hence either the slaughter of the animal or the fitting of a wide-bore fistula (e.g. in a sheep, at least $5 \mathrm{~cm}$. internal diameter) is required.

Sampling from the liquid portion is only slightly less difficult. In the large rumens of cattle, considerable stratification of the solutes has been noted (Pearson \& Smith, 1943; Smith et al. 1956). There are no records of similar differences in the much smaller rumens of sheep (see McDonald, 1952) and Boyne et al. (1957) and Purser \& Moir (1959) found only slight differences in protozoal concentration from top to bottom of a sheep's rumen. Another source of error in the preparation of a liquid sample lies in the method of removing the solids. In straining through gauze, muslin, etc., the feed particles mat together rapidly and form an efficient filter for at least the larger organisms if special precautions are not taken. Boyne et al. (1957) used a method of wet sieving that largely obviated this difficulty, but resulted in inconveniently large volumes of fluid in the sample which had then to be concentrated.

A description of an attempl to develop a simple technique to count all the microorganisms in the rumen with satisfactory accuracy, and to discover to what extent a count made on a sample of rumen liquor resembles a count made on a sample of whole rumen contents, is made in this paper. 


\section{METHODS}

Animals. All the animals used were Merino-English Leicester cross-bred ewes or wethers; they were fitted with rumen fistulas by Dr J. P. Hogan of this Laboratory. One group was fed $800 \mathrm{~g}$./day of a ration, R. 9, consisting of equal parts of lucerne chaff and wheaten chaff. A second group was grazing a pasture consisting predominantly of Lolium perenne and Trifolium subterraneum.

Preparation of samples. The standard technique was to remove not less than $100 \mathrm{ml}$. of rumen ingesta by suction through a glass tube of about $1 \mathrm{~cm}$. internal diam.; this material was then strained through nylon bolting cloth grade $6 \mathrm{XX}$ (nominal average diam. of holes $0.226 \mathrm{~mm}$.), stirring the material in the cloth whilst straining, and kneading and squeezing the solids remaining in the cloth after the removal of most of the fluid to minimize the entrapment of micro-organisns by feed particles. Five ml. of the strained fluid were then diluted to $25 \mathrm{ml}$. with formol saline $(10 \%(\mathrm{v} / \mathrm{v})$ formaldehyde solution in $0.85 \%(\mathrm{w} / \mathrm{v})$ sodium chloride). Counts on these samples were called 'standard counts'.

In all dilutions pipettes with the tips ground down to an approximate $2 \mathrm{~mm}$. bore were used so that the mouth would not be blocked by feed particles. Samples were taken immediately after vigorous mixing so that the denser micro-organisms such as the holotrich protozoa would not have settled appreciably.

To obtain the true total count the entire rumen contents were removed through a $5 \mathrm{~cm}$. diam. fistula or in the case of the grazing animals, immediately after slaughter, and mixed thoroughly in a bucket; about $50 \mathrm{~g}$. were transferred into a weighed flask containing $200 \mathrm{ml}$. formol saline, mixed and strained through bolting cloth as above. The fluid portion was labelled 'strained sample'; the solids were then mixed thoroughly with $100 \mathrm{ml}$. formol saline and strained again. This fluid portion was labelled 'washed sample'. The remaining solids were mixed with $50 \mathrm{ml}$. formol saline, blended in a homogenizer (Measuring and Scientific Equipment Itd., London) at full speed for 4 min., and strained as before. This process of blending and straining was repeated to a total of seven times, when microscopical examination showed that all heavily colonized plant material had disappeared, presumably through disintegration, and remaining plant material showed only a very few adherent bacteria; there were, however, still a number of bacteria free in the fluid. Most of these latter were removed by mixing the solids with three batches of $50 \mathrm{ml}$. formol saline in turn, centrifuging at about $50 \mathrm{~g}$ for $5 \mathrm{~min}$. and straining both the supernatant and the bulky deposit. All these fluid portions were combined and labelled 'blended sample'. The true total count was then taken to be the sum of the counts on the strained, washed and blended samples.

Samples labelled 'true fluid sample' were obtained by taking about $200 \mathrm{~g}$. of the mixed whole rumen contents, straining and diluting as for the standard sample.

Counting the protozoa. Protozoa were counted in a Manners counting chamber (depth $0.2 \mathrm{~mm}$., total volume $10 \mathrm{~mm}^{3}$; obtained from Hawksley and Sons Ltd., London), filling the chamber from a Pasteur pipette with bore at the tip about $1.5 \mathrm{~mm}$. Vigorous mixing and rapid handling ensured that the denser microorganisms did not settle out appreciably during this procedure. The counting chamber was inspected visually to detect any obvious unevenness in distribution of the larger particles: if found, such a preparation was rejected. Oxford (1955) and 
Boyne et al. (1957) expressed doubts as to the suitability of a counting chamber $0.2 \mathrm{~mm}$. deep for counting organisms whose length was of the same order of magnitude. However, it should be noted that the largest holotrich protozoa were usually much less than $100 \mu$ in cross-sectional diameter and the larger oligotrichs were flattened and did not appear to exceed about $50 \mu$ in depth. Careful examination has not shown any evidence for accumulation of large micro-organisms outside or near the filling end of the slicle; however, the very large organisms have been comparatively rare in all the specimens examined in this work. It should also, of course, be noted that all samples examined had already passed through holes of slightly over $200 \mu$ diameter in the bolting cloth; there was no evidence that any large protozoa were retained in this process. The distribution of micro-organisms over the slide was not quite even; the quarter of the ruled area farthest from the filling end showed a progressively increasing concentration, the farthest squares containing about $10 \%$ more entodinia than the nearest; this figure was slightly greater for oscillospiras, and less for selenomonads (organism no. 3-5 of Moir \& Masson (1952), who describe a number of such organisms). This effect was probably due to the properties of particles flowing in fluids (Mattern, Brackett \& Olson, 1957).

The ciliate protozoa were identified usually only as far as genera; no attempt was made to identify the species of every cell examined, in view of the difficulty of identifying internal structures in a protozoon engorged with, e.g. starch grains and perhaps overlaid by feed particles, and the possibility of the sort of situation described by Lubinsky (1957) where a number of apparently distinct species assumed very similar forms.

Flagellate protozoa, large, morphologically distinctive bacteria such as oscillospiras, and protists of uncertain status such as selenomonads, were also counted in the Manners chamber. Dead protozoa, recognizable by altered refractility and morphological degeneration, and dividing or conjugating protozoa were also counted in some cases.

Usually one filling of the counting chamber was adequate.

Counting the bacteria. Total bacteria were counted in a Helber counting chamber, taking the precautions outlined by Warner (1956). Usually two fillings of the counting chamber were used to provide a further check on satisfactory technique.

Differential counts were done on Gram-stained preparations of a $5 \mu$ l. sample spread as evenly as possible over $2 \mathrm{~cm} .{ }^{2}$ and dried rapidly; the micro-pipette used had an orifice of about $0.1 \mathrm{~mm}$. A total of about 2000 cells was counted. The bacteria were divided into a convenient number of morphological groups and the total number in each group calculated from the total count found in the Helber chamber and the proportion of each group found on the stained slide.

Using these counting techniques, there appeared to be little difficulty in distinguishing between bacteria and particles from disrupted plant cells; the typical shape and definite external membrane of the bacteria were readily recognized. It remains possible that very small micro-organisms, near or below the limits of resolution of the microscope, escaped being counted. 


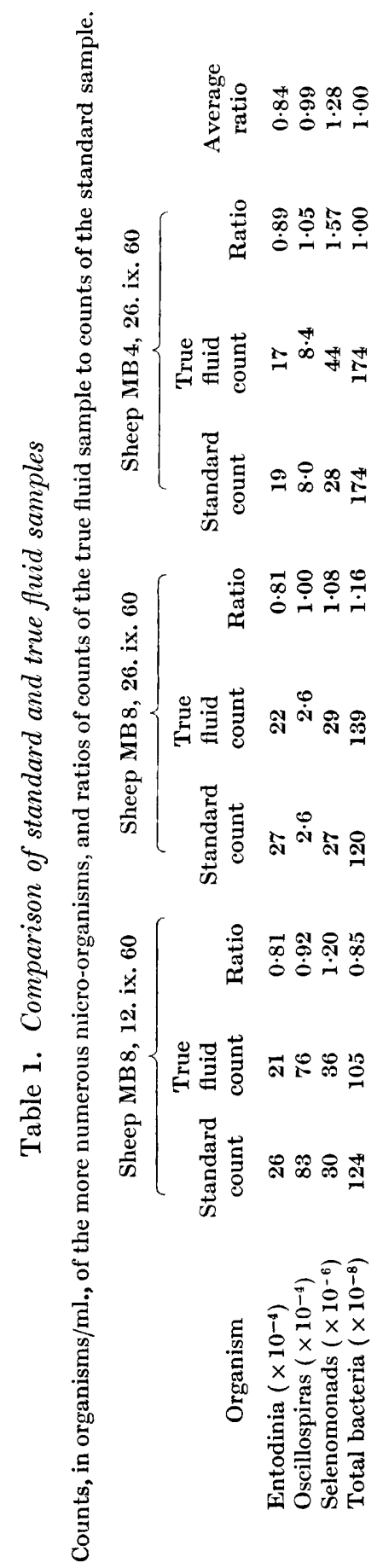




\section{RESULTS}

Counting accuracy. The counts made in counting chambers appeared to conform to the statistics of a Poisson distribution. The separate counts quoted in this paper can be stated, with $95 \%$ confidence, to have an error not exceeding $20 \%$, the total bacterial counts having an error of less than $10 \%$. Counts of the less numerous organisms, which were less accurate, are not quoted here. The accuracy of the differential counts was not checked.

Sampling accuracy. Counts on replicate standard samples taken at the same time showed agreement nearly as good as that between replicate counts on the same sample. A limited comparison of standard and true fluid samples, given in Table 1, shows that a random standard sample gives a fair measure of the concentration of micro-organisms in the fluid part of the rumen ingesta.

Comparison of standard and true total counts. A comparison of counts on the

\section{Table 2. Comparison of standard and true total counts}

Samples were taken from animals on R. 9 ration, 29 hr. ('fasting') or 5 hr. ("feeding') after the presentation of the feed. Samples were taken from grazing animals, $25 \mathrm{hr}$. ('fasting') or 2-3 hr. ('feeding') after removal from the pasture. The true total count is the sum of the counts of the strained, washed and blended samples. Confidence limits for the true total count were calculated from the results actually obtained, not derived from the limits of the constituent parts.

\begin{tabular}{|c|c|c|c|c|c|c|}
\hline \multirow[b]{2}{*}{ Organism } & \multirow[b]{2}{*}{ Ration } & \multirow{2}{*}{$\begin{array}{c}\text { No. } \\
\text { of } \\
\text { sheep }\end{array}$} & \multicolumn{4}{|c|}{$\begin{array}{l}\text { Counts and } 80 \% \text { confidence limits relative to a standard } \\
\text { count of } 100\end{array}$} \\
\hline & & & Strained & Washed & Blended & True total \\
\hline \multirow[t]{6}{*}{ Entodinia } & R. 9 & & & & & \\
\hline & Fasting & 6 & $65 \pm 4$ & $8 \pm 1$ & $6 \pm 1$ & $79 \pm 3$ \\
\hline & Feeding & $\ddot{z}$ & $80 \pm 5$ & $18 \pm 5$ & $4 \pm 3$ & $102 \pm 5$ \\
\hline & Pasture & & & & & \\
\hline & Fasting & $i^{*}$ & $63,47,190$ & $14,12,18$ & $10,6,14$ & $87,65,222$ \\
\hline & Feeding & 8 & $66 \pm 8$ & $14 \pm 1$ & $5 \pm 1$ & $85 \pm 8$ \\
\hline \multirow[t]{6}{*}{ Oscillospiras } & R. 9 & & & & & \\
\hline & Fasting & 6 & $81 \pm 9$ & $4 \pm 1$ & $4 \pm 1$ & $89 \pm 9$ \\
\hline & Feeding & 3 & $109 \pm 27$ & $11 \pm 3$ & $3 \pm 3$ & $123 \pm 24$ \\
\hline & Pasture & & & & & \\
\hline & Fasting & $3 *$ & $112,82, \dagger$ & $72,16, \dagger$ & $3,5, \dagger$ & $187,103, \dagger$ \\
\hline & Feeding & 3 & $133 \pm 33$ & $41 \pm 31$ & $7 \pm 5$ & $182 \pm 67$ \\
\hline \multirow[t]{6}{*}{ Selenomonads } & R. 9 & & & & & \\
\hline & Fasting & 6 & $56 \pm 4$ & $2 \pm 1$ & $4 \pm 1$ & $62 \pm 3$ \\
\hline & Feeding & 3 & $93 \pm 21$ & $8 \pm 1$ & $14 \pm 7$ & $115 \pm 27$ \\
\hline & Pasture & & & & & \\
\hline & Fasting & $3^{*}$ & $68,65,600$ & $2,1,11$ & $5,4,33$ & $75,70,64$ \\
\hline & Feeding & 3 & $73 \pm 9$ & $1 \pm 1$ & $6 \pm 1$ & $80 \pm 9$ \\
\hline \multirow[t]{6}{*}{ Total bacteria } & R. 9 & & & & & \\
\hline & Fasting & 6 & $92 \pm 7$ & $31 \pm 3$ & $129 \pm 20$ & $252 \pm 15$ \\
\hline & Feeding & 3 & $89 \pm 8$ & $34 \pm 7$ & $204 \pm 48$ & $327 \pm 54$ \\
\hline & Pasture & & & & & \\
\hline & Fasting & 3* & $58,87,100$ & $25,52,17$ & $90,316,98$ & $173,455,215$ \\
\hline & Feeding & 3 & $117 \pm 12$ & $39 \pm 8$ & $199 \pm 21$ & $355 \pm 33$ \\
\hline
\end{tabular}

* No statistical treatment was given to these data. The last figure in each column of this row refers to an animal whose rumen contents appeared abnormal; there were extensive adhesions between the rumen wall and the peritoneum in the neighbourhood of the fistula. 'The remaining figures refer to two apparently normal animals.

$\dagger$ Figures not recorded because concentrations were too low for accurate counting. 


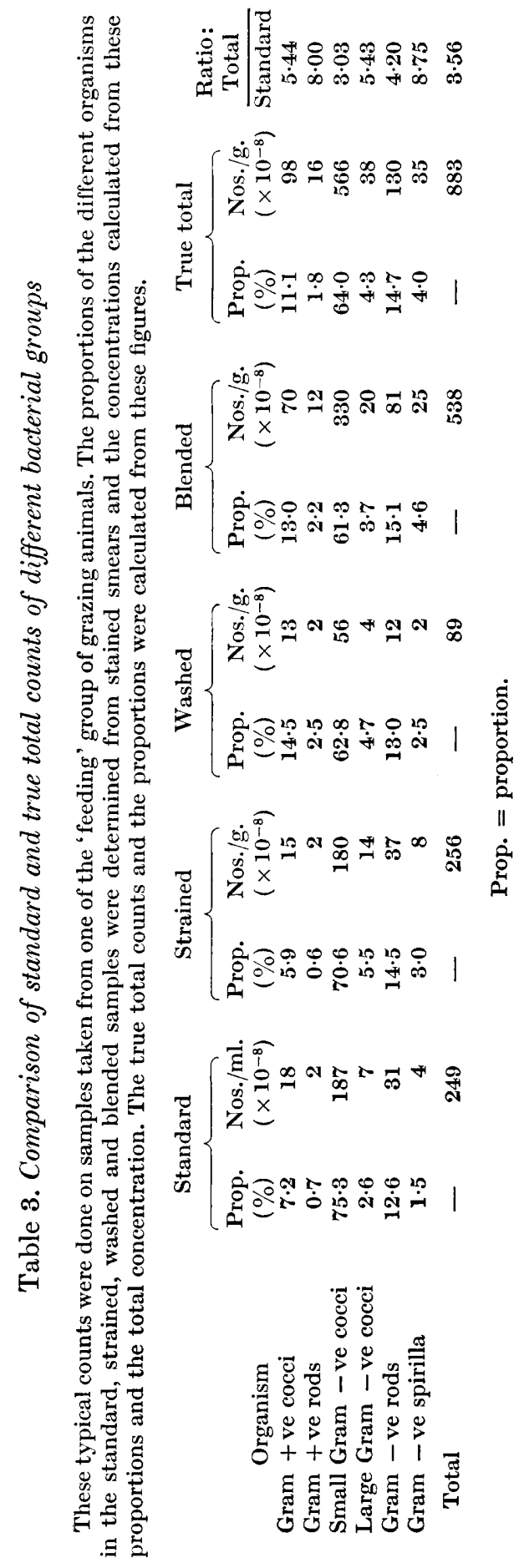


standard, strained, washed and blended samples and the true total counts for four groups of organisms and twelve animals examined on fifteen occasions is shown in 'Table 2; three of the animals on R. 9 diet were examined both 'feeding' and 'fasting'. Differential bacterial counts for one animal are given in Table 3; a basically similar picture was obtained with the other animals but the details varied in a way that made averages meaningless, probably due to different behaviour in the fractionating process of the species that made up any one group as counted, and to the proportions of these species in the group differing from animal to animal. In all cases, however, there was a increased proportion of spirilla and a decreased proportion of small Gram-negative cocci in the blended samples as compared with the others.

In many cases the standard counts of the various micro-organisms were fairly close to the true total counts, but the following differences were noted:

(a) One animal showed widely discrepant figures; in this case the considerable adhesions round the rumen fistula probably interfered with rumen motility and hence mixing in vivo so that the sampling error was much larger than usual.

(b) In a number of cases the standard count was higher than the true total. This could be partly due to the standard count being numbers per ml. of fluid, while the total count was numbers per g. of total contents, including the fluid and a considerable amount of solid material; but the fact that this effect was more marked with lasting specimens, containing presumably proportionately less feed material, would indicate that other factors were involved.

(c) Where the standard count was less than the true total count, this would appear to be due either to mechanical entrapment by feed particles of organisms which could be frecd by wasling the solids, e.g. oscillospiras, or to the presence within the plant material of organisms which needed disruption of the plant material to be freed, e.g. total bacteria. Inspection of the differential bacterial counts in Table 3 would suggest that this latter applied more to some groups of bacteria than to others; the spirilla particularly would appear to be associated with feed particles in this way.

\section{DISCUSSION}

The findings of Table 1 confirm those of Boyne et al. (1957) and Purser \& Moir (1959) and indicate that there are no marked differences in microbial population from place to place in the rumen under the conditions of these cxperiments. That this may not be always true is suggested, first, by the differences in solute concentrations found in the rumens of cattle and referred to earlier, which, by providing a different environment, must surely affect the microbial population; and secondly, by the results of microscopical examination of fresh rumen liquor on a warm stage, showing that there are many local concentrations of single or a few species of bacteria or protozoa, sometimes very dense, round particular points, sometimes identifiable as feed particles. Whenever conditions in the rumen are such that the different kinds of feed particle tend to separate, it can be expected that both the microbial and the solute concentrations will differ from place to place. The rations used in this investigation were not such as to make one expect this layering of feed constituents to be considerable.

It has been customary and convenient to count the micro-organisms in a sample of rumen liquor and assume that these counts were indicative of the true total 
counts. Tables 2 and 3 give some measure of the validity of this assumption. It would appear that usually only a moderate though variable error is incurred in making this assumption, except in the case of the bacteria, and particularly the spirilla, where the error is larger. In special circumstances, such as where rumen motility is impeded, as was presumably the case in the animal with adhesions round the fistula, the error can be very large.

There are indications that the ratio of true total to standard count is perhaps characteristic of the organism, the ration, and the time after feeding. This suggests that if these factors are maintained constant, and if effects such as those found in the animal with the rumen adhesions can be avoided, then changes in the standard count would fairly accurately reflect changes in the true total count.

In any attempt to interpret events in the rumen, the advantage of microbial counts that differentiate as much as possible between organisms must be emphasized, even though it is not yet possible to apportion a given reaction between the organisms present that are capable of carrying out that reaction. In a microbial population whose members differ as much in size and in metabolic activity as the different rumen organisms, a figure for total numbers alone is relatively meaningless.

The techniques that have been described to date for differential cultural counts of bacteria are very time-consuming. The direct methods for bacteria and protozoa described here are more speedy. A considerable number of morphological groups can be recognized and counted: in the case of the larger organisms, where the group can often be made to correspond to the species, the significance of the group is susceptible to study. Counting accuracy can be controlled by varying the total number of cells counted, if necessary filling several chambers or concentrating or diluting the sample. With a probable loss of some accuracy, quite small samples can be used.

Thanks are due to Dr J. P. Hogan for access to his sheep and to Mr K. Ayers for technical assistance. Mr H. Weiler, of the C.S.I.R.O. Division of Mathematical Statistics, gave advice on the statistical treatment of the results.

\section{REFERENCES}

ADam, K. M. G. (1951). The quantity and distribution of the ciliate protozoa in the large intestine of the horse. Parasitology, 41, 301.

Boyne, A. W., Eadie, J. M. \& RaITt, K. (1957). The development and testing of a method of counting rumen ciliate protozoa. J. gen. Microbiol. 17, 414.

Bryant, M. P. \& Burkey, L. A. (1953). Cultural methods and some characteristics of some of the more numerous groups of bacteria in the bovine rumen. J. Dairy Sci. 36, 205.

Ferber, K. E. (1928). Die Zahl und Masse der Infusorien im Pansen und ihre Bedeutung für den Eiweissaufbau beim Wiederkäuer. Z. Tierz. ZüchtBiol. 12, 31.

Gutierrez, J. (1955). Experiments on the culture and physiology of holotrichs from the bovine rumen. Biochem. J. 60, 516.

Hungate, R. E. (1942). The culture of Eudiplodinium neglectum with experiments on the digestion of cellulose. Biol. Bull., Woods Hole, 83, 303.

KöHLer, W. (1940), Versuche über die zahlenmässige Veränderung der natürlichen Bakterienflora in den Verdauungsorganen der Wiederkäuer. Arch. Mikrobiol. 11, 432.

Lengemann, F. W. \& Allen, N. N. (1955). The development of rumen function in the dairy calf. I. Some characteristics of the rumen contents of cattle of various ages. J. Dairy Sci. 38, 651. 
Lubinsky, G. (1957). Studies on the evolution of the Ophryoscolecidae (Ciliata: Oligotricha). 1. A new species of Entodinium with 'caudatum', 'loboso-spinosum' and 'dubardi' forms, and some evolutionary trends in the genus Entodinium. Canad. J. Zool. 35, 111.

MCDonald, I. W. (1952). The role of ammonia in ruminal digestion of protein. Biochem. $J$. $51,86$.

Mattern, C. F. 'T., Brackett, F. S. \& Olson, B. J. (1957). Determination of number and size of particles by electrical gating: blood cells. J. appl. Physiol. 10, 56.

MoIr, R. J. \& Masson, M. J. (1952). An illustrated scheme for the microscopic identification of the rumen micro-organisms of sheep. J. Path. Bact. 64, 343.

MoIr, R. J. \& Somers, M. (1957). Ruminal flora studies. VIII. The influence of rate and method of feeding a ration upon its digestibility, upon ruminal function, and upon the ruminal population. Aust. J. agric. Res. 8, 253.

Oxford, A. E. (1955). Parasitological reviews. The rumen ciliate protozoa. Exp. Parasitol. 4, 569 .

Pearson, K. M. \& Smith, J. A. B. (1943). The utilization of urea in the bovine rumen. 1. Methods of analysis of the rumen ingesta and preliminary experiments in vivo. Biochem. J. 37, 142.

Purser, D. B. \& Moir, R. J. (1959). Ruminal flora studies in the sheep. IX. The effect of $\mathrm{pH}$ on the ciliate population of the rumen in vivo. Aust. J. agric. Res. $10,555$.

Smith, J. A. B. \& Baker, F. (1944). The utilization of urea in the bovine rumen. 4. The isolation of the synthesized material and the correlation between protein synthesis and microbial activity. Biochem. J. 38, 496.

Smith, P. H., Sweeney, H. C., Rooney, J. R., KIng, K. W. \& Moore, W. E. C. (1956). Stratification and kinetic changes in the ingesta of the bovine rumen. J. Dairy Sci. 39, 598.

van Der Wath, J. G. (1948). Studies on the alimentary tract of Merino sheep in South Africa. XII. A technique for the counting of ruminal bacteria. Onderstepoort $J$. vet. Sci. 23, 385.

van der Wath, J. G. \& Myburghr, S. J. (1941). Studies on the alimentary tract of Merino sheep in South Africa. VI. The role of infusoria in ruminal digestion with some remarks on ruminal bacteria. Onderstepoort J. vet. Sci. 17, 61 .

WARNer, A. C. I. (1956). Criteria for establishing the validity of in vitro studies with rumen micro-organisms in so-called artificial rumen systems. J. gen. Microbiol. 14, 733. 